[18] Obermeier, M., Schennach-Wolff, R., Meyer, S., Moller, H.-J., Riedel, M., Krause, D., Seemuller, F. (2011). Is the PANSS used correctly? A systematic review. BMC Psychiatry, 11 (1). doi: 10.1186/ 1471-244x-11-113

[19] Nielzen, S. (2008). Psychoacoustics \& Schizophrenia. J. Der Nervenarzt, 79, 193.

[20] Nielzen, S., Kallstrand, J., Larsson, L. (2004). Clinical psychoacoustics can support an objective diagnosis of schizophrenia. J. Lakartidningen, 101, 15-16.

[21] Besh, L. V., Matsiura, O. I., Novikevych, S. Z., Yanchinska, O. V, Gutor, T. H. (2014). Analysis of the sensitization structure of children with seasonal allergies. Problems of clinical pediatrics, 1 (23), 23-32.

\title{
MEDICAL AND SOCIAL CHARACTERISTICS OF PHYSICIANS ATTENDING POSTGRADUATE TRAINING COURSES (SOCIAL SURVEY)
}

\author{
Orest Sichkoriz \\ Department of Pediatric Infectious Diseases \\ Danylo Halytsky Lviv National Medical University \\ 69 Pekarska str., Lviv, Ukraine, 79010 \\ sichkorizoye@gmail.com
}

\begin{abstract}
The paper studies professional, social and psychological aspects concerned with a practical activity of physicians referred to attend postgraduate training courses at Danylo Halytsky Lviv National Medical University.

Aim. To develop the recommendations on the improvement in the system of postgraduate medical education under the conditions of general reform in the health care system.

The research was done by the survey method in the form of standardized (formalized) interview that was applied as the main approach to the process of collecting social and psychological information.The survey included 823 physicians referred to attend postgraduate training courses at Danylo Halytsky Lviv National Medical University. The working experience of postgraduate course attendants was the following: up to 5 years $-25.39 \pm 1.52 \%, 5-10$ years $-21.39 \pm 1.43 \%, 11-15$ years $-11.79 \pm 1.12 \%, 16-20$ years $9.96 \pm 1.04 \%, 21-30$ years $-16.89 \pm 1.31 \%$, more than 30 years $-14.58 \pm 1.23 \%$.

The majority of questioned medical workers ( $74.24 \pm 1.52 \%)$ feel calm and happy at their working place. However, the received data indicates that $23.09 \pm 1.47 \%$ of the responders feel disturbance and $1.94 \pm 0.48 \%$ experience fear at work. The analysis of the research results allowed differentiating five sharp problems which are very topical and significant at the medical institution where the physicians have been performing their practice. They can be ranged in the following way: the job compensation ( $42.93 \pm 2.09 \%)$, absence of modern medical equipment $(26.65 \pm 1.87 \%$ ), organization of the working process $(22.90 \pm 1.78 \%)$, reorganization ( $7.69 \pm 1.13 \%)$, extra documentation $(7.33 \pm 1.10 \%)$. The carried out survey permitted to determine the psychological atmosphere at medical institutions there the course attendants have been practicing. The conflicts are not a characteristic feature of medical institutions, since almost half of the responders indicated the absence of conflicts with higher managers ( $52.86 \pm 1.74 \%)$, direct managers $(43.01 \pm 1.73 \%)$, subordinate personnel $(43.38 \pm 1.73 \%)$. This index is somewhat lower concerning the colleagues and patients. It amounts for $36.33 \pm 1.68 \%$ and $33.17 \pm 1.64 \%$ respectively.

The physicians practicing in medicine and prevention as well as dentistry branches are most disturbed by the lack of financial sources. More than a half of responders $(73.86 \pm 2.70 \%)$ indicated it by their answers. Other responses included the absence of perspectives $-68.18 \pm 2.87 \%$, extreme, stressful living conditions $-25.38 \pm 2.68 \%$, personal present health status $-20.08 \pm 2.47 \%$, personal lack of confidence $-9.47 \pm 1.80 \%$ (the number of responses was not restricted).

The carried out work has showed the necessity of introducing the specialized course "State medical policy". It should be aimed at delivering the information on the status, perspectives, reforming changes and the expected outcomes resulting from these factors in the branch of medicine. In order to decrease the negative influence of the professional burnout, it is recommended to plan the specialized training classes that are directed on the prevention of the listed above phenomena.
\end{abstract}

Keywords: postgraduate education, standardized interview, medical and social aspects, health care. 


\section{Introduction}

The native system of health care is currently in search of ways out of a crisis situation and building a new model close to European standards. And this process necessarily requires a change in the paradigm of basic secondary and higher medical education [1, 2].

That is why, in the context of the rapid development of innovative technologies and evidence-based medicine, introduction into the practice of health care institutions of new methods of treatment and diagnosis of diseases, the latest information and modern telemedicine technologies that enable to work in a single professional world of European space, nowadays the issue of reforming the system of medical education is acute [3, 4].

Improving the quality of professional training of future doctors in accordance with world and European standards in order to increase the competitiveness of native higher medical education, optimizing the conditions for international mobility of medical students and expanding the capabilities of Ukrainian medical professionals in the native and international labor markets are conditioned by the proclamation of course of Ukraine on European integration $[5,6]$.

The higher medical education is provided by a network of medical, pharmaceutical and dental institutes, academies and universities, which carry out higher professional training, retraining and improving skill, as well as postgraduate education of medical personnel of various levels [7, 8].

Each year, higher medical (pharmaceutical) educational institutions in Ukraine graduate over 10 thousand students, whereas in the United States of America, with a population of about 319 million, the total number of graduates of all medical schools varies from 17 to 19 thousand people [9].

Each year the state spends hundreds of millions of budget funds on training specialists: the cost of a year of studying a medical student in Ukraine varies from 13 to 27 thousand hryvnias depending on the specialty and the educational institution. At the same time, international payments are fundamentally different. So, in the UK, the training costs 50 thousand pounds, and in the US, the cost of training a medical student can reach 90 thousand dollars for a year.Against this backdrop, Ukrainian expenditures per student seem to be underestimated and a priori mean that it is impossible to prepare future doctors qualitatively [10, 11].

Modern society has faced social, political and economical changes causing increased psycho-emotional exertion and the onset of psychological problems which influence the lives of overall population and the physicians, in particular[12]. Medical practice is characterized by the intellectual difficulty, monotonous activities, increased risk, responsibility, moral issues, and interpersonal conflicts [13]. It is associated with frequent stressful situations caused by the necessity to practice in the conditions of increased intellectual and psycho-emotional exertion, time and information deficiency, responsibility for the health and lives of patients [14, 15].

Satisfying individual requirements of self-realization and self-actualization is known as one of the main factors of professional identification $[14,16]$. It contributes to the emotional status and, thus, positively influences the professional activity of the individual [17]. The leading place in this process belongs to the institution which is responsible for both the formation and the development of professional qualities of the specialist $[18,19]$. The psychological climate in the team of medical specialists and their effective activity are significantly influenced by such conditions as group cooperation and mutual understanding between all colleagues regardless of the held post [19, 20].

\section{Aim of the research}

Develop the recommendations on the improvement in the system of postgraduate medical education under the conditions of general reform in the health care system.

\section{Materials and methods}

The research was performed by the survey method in the form of standardized (formalized) interview that was applied as the main approach to the process of collecting social and psychological information.The survey included 823 physicians referred to attend postgraduate training courses at Danylo Halytsky Lviv National Medical University. The working experience of postgraduate course attendants was the following: up to 5 years $-25.39 \pm 1.52 \%, 5-10$ years $-21.39 \pm 1.43 \%$, 
$11-15$ years $-11.79 \pm 1.12 \%, 16-20$ years $-9.96 \pm 1.04 \%, 21-30$ years $-16.89 \pm 1.31 \%$, more than 30 years $-14.58 \pm 1.23 \%$.

In the statistical processing of the primary data, the minimum required number of observations by the method of V. Paniotto was determined, as well as the calculation of the relative values and their standard errors using the Laplace function.

\section{Results of research}

The analysis of the attitude of the responders towards the clinical or pharmaceutical institution where they have been presently working has showed that more than a half of a staff $62.45 \pm 1.69 \%$ - consider them similar to other establishments of the same direction, the third of the participants thinks that their institution is better than other ones $-30.01 \pm 1.60 \%$, while $6.56 \pm$ $\pm 0.86 \%$ are confirmed that it is worse than others.

The majority of questioned medical workers (74.24 $\pm 1.52 \%)$ feel calm and happy at their working place. However, the received data indicates that $23.09 \pm 1.47 \%$ of the responders feel disturbance and $1.94 \pm 0.48 \%$ experience fear at work.

The personal sensations at a work place lead to the satisfaction which reflects into the performance of the professional duties. The responses to the questions aimed to find out satisfaction from work fully prove this fact. Thus, $69.99 \pm 1.60 \%$ stated that they were fully or mainly satisfied, and $24.79 \pm 1.51 \%$ indicated that they were not very satisfied (it can be suggested that these are individuals who feel disturbed at work). A total of $4.50 \pm 0.72 \%$ questioned physicians of different specialization appeared unsatisfied at their work place (Fig. 1).

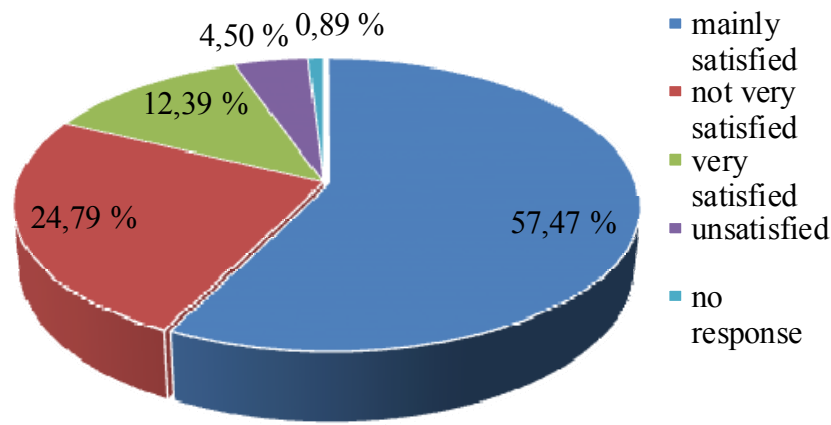

Fig. 1. Satisfaction (\%) of physicians at a work place

In our opinion, highlighting of some factors that can possibly influence the level of satisfaction at work is very important. The analysis of the survey results shows that most responders are fully or mainly satisfied: with working specifics $-84.20 \pm 1.27 \%$, working conditions $68.65 \pm 1.62 \%$, work organization $-71.20 \pm 1.58 \%$, their specialization $-86.51 \pm 1.19 \%$, a work place $-73.27 \pm 1.54 \%$, engagement in the process of responsible decision making $-72.42 \pm 1.56 \%$, working regimen $-70.47 \pm 1.59 \%$, and only $32.20 \pm 1.63 \%$ - are satisfied with the existing system of compensation for work.

Depending on their specialty the physicians had different points of view on the information delivery. Thus, more than a half of surgeons, internists, pediatricians, and dentists are fully or mainly satisfied with the information delivery in the branches. And his share makes up - 61.36 $\pm 2.06 \%$ of responders. On the other hand, more than the third of medicine and prevention or pharmacy specialists expressed dissatisfaction with the existing information delivery in their branches and resulted in $43.18 \pm 3.05 \%$ of unsatisfied and not very satisfied individuals.

The similar situation has been observed while analyzing the responses to the question concerning the possibilities of future career rise. The surgeons, internists, pediatricians and dentists are fairly optimistic about the ideas of improving their professional skills and career. In general, $14.49 \pm 1.49 \%$ and $45.44 \pm 2.11 \%$ of the responders are fully satisfied or mainly satisfied respectively. More than a half of the physicians $(54.55 \pm 3.06 \%)$ of the medicine and prevention or pharmacybranches are either unsatisfied or not very satisfied by their perspectives of professional rise. This 
situation can be caused by current reforms in these directions of medicine, and it is closely related to the level of information delivery on the real status of the reforms.

The analysis of the research results allowed differentiating five sharp problems which are very topical and significant at the medical institution where the physicians have been performing their practice. They can be ranged in the following way: the job compensation (42.93 \pm $\pm 2.09 \%$ ), absence of modern medical equipment $(26.65 \pm 1.87 \%$ ), organization of the working process $(22.90 \pm 1.78 \%$ ), reorganization ( $7.69 \pm 1.13 \%$ ), extra documentation $(7.33 \pm 1.10 \%$ ) (Fig. 2).

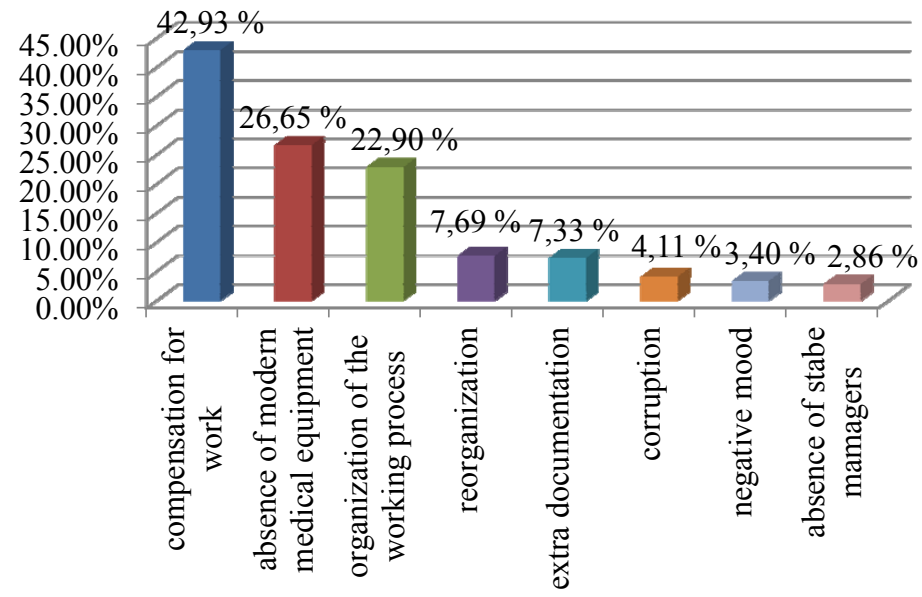

Fig. 2.The problems considered by the physicians (surgeons, internists, pediatricians and dentists) as really topical and significant at their current medical institutions

The specialists of medicine and prevention as well as pharmacy branches have somewhat different range of problems. Thus, the first position in the list belongs to the compensation for work $(39.77 \pm 3.01 \%)$, the second - organization of a working process $(34.09 \pm 2.92 \%)$, the third - reorganization (18.18 $\pm 2.37 \%$ ), the forth - extra documentation ( $3.03 \pm 1.06 \%$ ), andthe fifth - absence of stable managers $(2.27 \pm 0.92 \%)$. The physicians of the listed specialties are the least disturbed by the modern medical equipment that was proved by $0.38 \pm 0.38 \%$ of the responders. This is caused by the specificity of their work (Fig. 3).

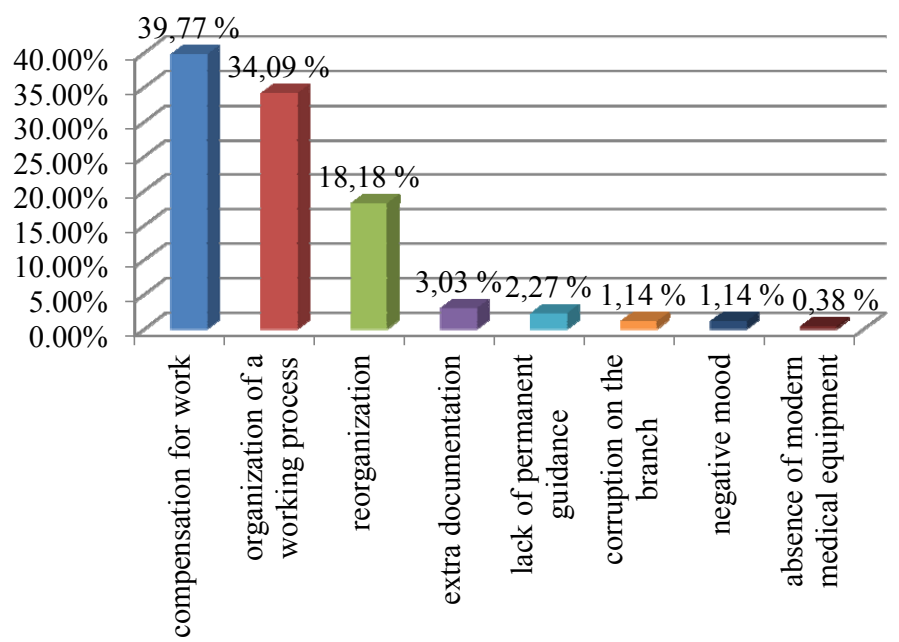

Fig. 3.The problems considered by the physicians (medicine and prevention, pharmacy branches) as really topical and significant at their current medical institutions

Another issue is the mood characteristic for the professionals in all scopes of medicine. This issue can be defined as contradictory and polar as the responders indicated more than one 
response. Somewhat more than the third of them $38.03 \pm 1.69 \%$ feel optimistic but another third of the survey participants feel disturbance and anxiety $(33.66 \pm 1.65 \%)$, while $32.93 \pm 1.64 \%$ feel confident and calm, $14.46 \pm 1.23 \%$ - feel anger and irritation, and $8.02 \pm 0.95 \%$ are characterized by the feelings of fear and despair. To our mind, it can be closely connected with the social and political situation in the country and on the other hand with reorganization changes taking place in the health care branch.

\section{Discussion}

The carried out survey permitted to determine the psychological atmosphere at medical institutions there the course attendants have been practicing. The conflicts are not a characteristic feature of medical institutions, since almost half of the responders indicated the absence of conflicts with higher managers $(52.86 \pm 1.74 \%)$, direct managers $(43.01 \pm 1.73 \%)$, subordinate personnel $(43.38 \pm 1.73 \%)$. This index is somewhat lower concerning the colleagues and patients. It amounts for $36.33 \pm 1.68 \%$ and $33.17 \pm 1.64 \%$ respectively. The following situation can indicate the necessity of including the specialized courses and psychological trainings on conflictology into the curricula of postgraduate professional training.

In addition, the effectiveness and the results of the professional activity depend on personal factors and the degree of their manifestations in different individuals. It explains why we highlighted the problems of the personal character causing a particular worry in the responders. However, the thoughts of medical professionals divided according to the medical specialty. The physicians practicing in surgery, internal medicine, pediatrics and dentistry indicated the lack of financial sources $(62.08 \pm 2.05 \%)$, extreme and stressful conditions $(34.70 \pm 2.01 \%)$, absence of the perspectives $(31.84 \pm 1.97 \%)$, personal present health status $(21.1 \pm 1.73 \%)$, and misunderstandings with colleagues $(10.38 \pm 1.29 \%)$ (Table 1).

Table 1

Problems of the personal character causing the most of disturbance

\begin{tabular}{|c|c|c|c|}
\hline \multirow[b]{2}{*}{ No. } & \multirow[b]{2}{*}{ Personal factor } & \multicolumn{2}{|c|}{ Specialties } \\
\hline & & $\begin{array}{l}\text { surgery, internal medicine, } \\
\text { pediatrics and dentistry, \% }\end{array}$ & $\begin{array}{c}\text { Medicine and prevention, } \\
\text { pharmacy, } \%\end{array}$ \\
\hline 1 & Lack of financial sources & $62.08 \pm 2.05$ & $73.86 \pm 2.70$ \\
\hline 2 & Extreme, stressful conditions & $34.70 \pm 2.01$ & $25.38 \pm 2.68$ \\
\hline 3 & Absence of the perspectives & $31.84 \pm 1.97$ & $68.18 \pm 2.87$ \\
\hline 4 & Personal present health status & $21.11 \pm 1.73$ & $20.08 \pm 2.47$ \\
\hline 5 & Misunderstandings with colleagues & $10.38 \pm 1.29$ & $0.38 \pm 0.38$ \\
\hline 6 & $\begin{array}{l}\text { Insufficient level of personal } \\
\text { qualification }\end{array}$ & $9.30 \pm 1.23$ & $10.98 \pm 1.92$ \\
\hline 7 & Family problems & $8.94 \pm 1.21$ & $7.95 \pm 1.67$ \\
\hline 8 & Personal lack of confidence & $8.77 \pm 1.20$ & $9.47 \pm 1.80$ \\
\hline 9 & Loss of professional interest & $7.87 \pm 1.14$ & $6.06 \pm 1.47$ \\
\hline 10 & Alcohol abuse & $1.61 \pm 0.53$ & $0.76 \pm 0.53$ \\
\hline
\end{tabular}

The physicians practicing in medicine and prevention as well as dentistry branches are most disturbed by the lack of financial sources. More than a half of responders $(73.86 \pm 2.70 \%)$ indicated 
it by their answers. Other responses included the absence of perspectives $-68.18 \pm 2.87 \%$, extreme, stressful living conditions $-25.38 \pm 2.68 \%$, personal present health status $-20.08 \pm 2.47 \%$, personal lack of confidence $-9.47 \pm 1.80 \%$ (the number of responses was not restricted).

\section{Conclusions}

1. The research has showed that there is the necessity and a problem of changing the curricula by introducing the specialized courses like "State medical policy". The course must be aimed at delivering the information on the current status, perspectives, reforming changes and the expected outcomes resulting from these factors in the branch of medicine.

2. The analysis of the research results allowed differentiating five sharp problems which are very topical and significant at the medical institution where the physicians have been performing their practice. They can be ranged in the following way: the job compensation, absence of modern medical equipment, organization of the working process, reorganization, extra documentation.

3. In order to decrease the negative influence of the professional burnout, increase the stress barrier, improve the psychological climate in the medical team and perform professional duties effectively it is recommended to plan the specialized training classes that are directed on the prevention of the listed above phenomena.

\section{References}

[1] Artino, A. R., Cervero, R. M., DeZee, K. J., Holmboe, E., Durning, S. J. (2018). Graduate Programs in Health Professions Education: Preparing Academic Leaders for Future Challenges. Journal of Graduate Medical Education, 10 (2), 119-122. doi: 10.4300/jgme-d-18-00082.1

[2] Cervero, R. M., Artino, A. R., Daley, B. J., Durning, S. J. (2017). Health Professions Education Graduate Programs Are a Pathway to Strengthening Continuing Professional Development. Journal of Continuing Education in the Health Professions, 37 (2), 147-151. doi: 10.1097/ceh.0000000000000155

[3] Borysenko, A. V. (2016). Use of modern technologies of higher medical education in the organization of activities of subordinates within the framework of the credit transfer system. Modern Dentistry, 4, 110-113.

[4] Patel, P. (2016). An evaluation of the current patterns and practices of educational supervision in postgraduate medical education in the UK. Perspectives on Medical Education, 5 (4), 205-214. doi: 10.1007/ s40037-016-0280-6

[5] De Leeuw, R. A., Westerman, M., Nelson, E., Ket, J. C. F., Scheele, F. (2016). Quality specifications in postgraduate medical e-learning: an integrative literature review leading to a postgraduate medical e-learning model. BMC Medical Education, 16 (1). doi: 10.1186/s12909-016-0700-7

[6] Lysenko, O. (2016). Postgraduate education of doctors: description of basic concepts. Continuing Professional Education: Theory and Practice, 3-4, 23-28.

[7] Tkachuk, O. H. (2015). Formation of competency of leadership in future physicians. Young Scientist, 6, 139-141.

[8] Dolgopol, O. O. (2016). Features of evaluation of academic achievements of students in institutions of postgraduate medical education. Pedagogics and Psychology, 53, 58-65.

[9] Tekian, A., Artino, A. R. (2014). AM last page. Overview of doctoral programs in health professions education. Academic medicine: journal of the Association of American Medical Colleges, 89 (9), 1309. doi: 10.1097/acm.0000000000000421

[10] Evans, K. H., Thompson, A. C., O’Brien, C., Bryant, M., Basaviah, P., Prober, C., Popat, R. A. (2016). An Innovative Blended Preclinical Curriculum in Clinical Epidemiology and Biostatistics. Academic Medicine, 91 (5), 696-700. doi: 10.1097/acm.0000000000001085

[11] Al-Lamki, N., Al-Lamki, L. (2016). International Accreditation of Postgraduate Medical Education: Whither Its Role in Oman? Oman Medical Journal, 31 (1), 341-344. doi: 10.5001/omj.2016.01

[12] Catalanotti, J., Popiel, D., Johansson, P., Talib, Z. (2013). A Pilot Curriculum to Integrate Community Health Into Internal Medicine Residency Training. Journal of Graduate Medical Education, 5 (4), 674-677. doi: 10.4300/jgme-d-12-00354.1 
[13] Dang, T. M., Maggio, L. A. (2017). Supporting the Call to Action. Academic Medicine, 92 (3), 403-416. doi: 10.1097/acm.0000000000001532

[14] Dai, H., Fang, L., Malouin, R. A. et. al. (2013). Family Medicine Training in China. Family Medicine, 45 (5), 341-344.

[15] Lazurenko, O. O. (2015) Concept of Formation of Emotional Competence at Different Stages of Professional Training of a Physician. Scientific Bulletin of Kherson State University. Series: Psychological Sciences, 3, 113-116.

[16] Miller, V. A., Cousino, M., Leek, A. C., Kodish, E. D. (2014). Hope and Persuasion by Physicians During Informed Consent. Journal of Clinical Oncology, 32 (29), 3229-3235. doi: 10.1200/jco. 2014.55.2588

[17] Tkachenko, L. G. (2015). Training Vouchers for Persons Aged Over 45 Years as Tools of Active Labour Market Policy. Demography and Social Economy, 2 (24), 41-52. doi: 10.15407/ dse2015.02.041

[18] Ruden, V. V., Gutor, T. H. (2011). Methodology for conducting and evaluating the results of expert assessments (based on the example of implementation of a system of monitoring of health of population at the level of medical-sanitary care). Ukrainian medical journal, 2, 31-34.

[19] Liubinets, O. V., Khodor, O. Ye., Gutor, T. H. (2016). The effectiveness of the implementation of information systems in the institutions of health care according to the opinions of doctors-organizers. Eastern European Journal of Public Health, 1, 93-94.

[20] Vitenko, I. S. (2013). Psychological Adaptation of Family Doctor to Professional Activity. Vinnitsa: New Book, 132. 